\title{
Por uma gramática aplicada à prática sonora cravistica: duas vertentes nacionais para a compreensão do estilo nas execuções
}

\author{
Edmundo Hora (UNICAMP, Campinas, SP) \\ ephora@iar.unicamp.br
}

Resumo: Este artigo centra-se no processo da construção instrumental e na teoria aplicada à prática de execução, advinda do processo de difusão dos conhecimentos históricos por meio dos tratados de época em tempos recentes, aliando ainda elementos especificos significativos: partitura (Les Bergeries F. Couperin) e instrumentos musicais (cravos: francês e alemão do século XVIII), para a recuperação do estilo nacional.

Palavras chave: gramática aplicada; cravo; estilo nacional no século XVIII.

\section{An applied grammar for harpsichord sound production: two national schools to understand style in performance}

Abstract: This article focuses on the theory applied to performances practices arising from the diffusion of historical knowledge through the treatises of the time, yet combining special elements, namely: score (Les Bergeries F. Couperin) and musical instruments (French and German harpsichords of the eighteenth century).

Keywords: applied-grammar; harpsichord; national style in the eighteenth century.

\section{1 - Introdução}

Quando nos anos 60 do século XX as novas propostas de interpretação histórica para o Cravo - de acordo com os preceitos instruídos nos tratados antigos - tiveram seu ponto de partida, escolheu-se como modelo instrumental o cravo francês de Pascal-Joseph Taskin (1723-1793) ${ }^{1}$ que se encontra no Department of Early Keyboard Instruments da Edinburgh University - hoje conhecida como Russell Collection em Edinburgh (Ex.1). ${ }^{2}$

No catálogo ilustrativo desta coleção, lemos: "Um excepcionalmente excelente e importante instrumento entre toda a bem desenvolvida e típica escola francesa". E mais: "Uma inscrição pintada ao redor da rosácea traz - PASCAL TASKIN ELEVE DE BLANCHET" (1968, p.33), conforme ilustra o Ex.2.
De início, o processo histórico deste exemplar pode ser resumido da seguinte maneira: Em 1952, Raymond Russell o adquiriu em Paris de Mme Arlette Taskin, uma descendente das famílias Blanchet ${ }^{3}$ e Taskin, que afirmara ter sido este cravo propriedade do seu pai e que fora restaurado em 1882 por Louis Tomasini - provavelmente, portanto, a primeira restauração de um instrumento antigo já ao final do século XIX. Com a morte de Monsieur Taskin ele foi comprado pelo pianista Louis Diémer (1843-1919) ${ }^{4}$ e, ainda segundo ela - sua filha Arlette: "foi emprestado várias vezes para concertos em Paris" (Catálogo, p.33). Tomasini interessou-se também em construir instrumentos contribuindo para a restauração e uso dos instrumentos de época na Paris de 1895 pela Société des instruments anciens. 


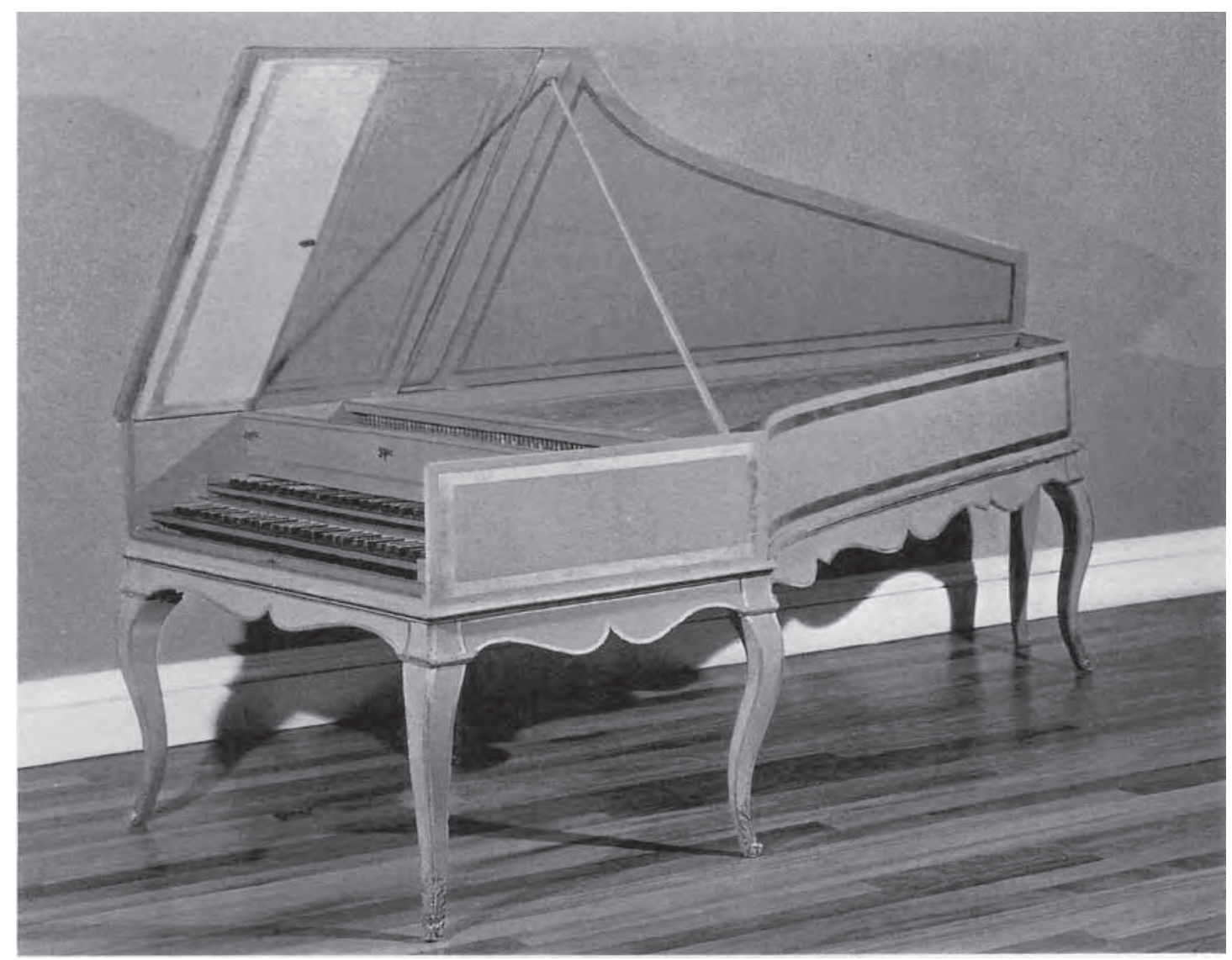

Ex.1 - Cravo Taskin. Paris, 1769.

(Fonte: Catálogo da Russell Collection of Early Keyboard Instruments, 1968. p.32)

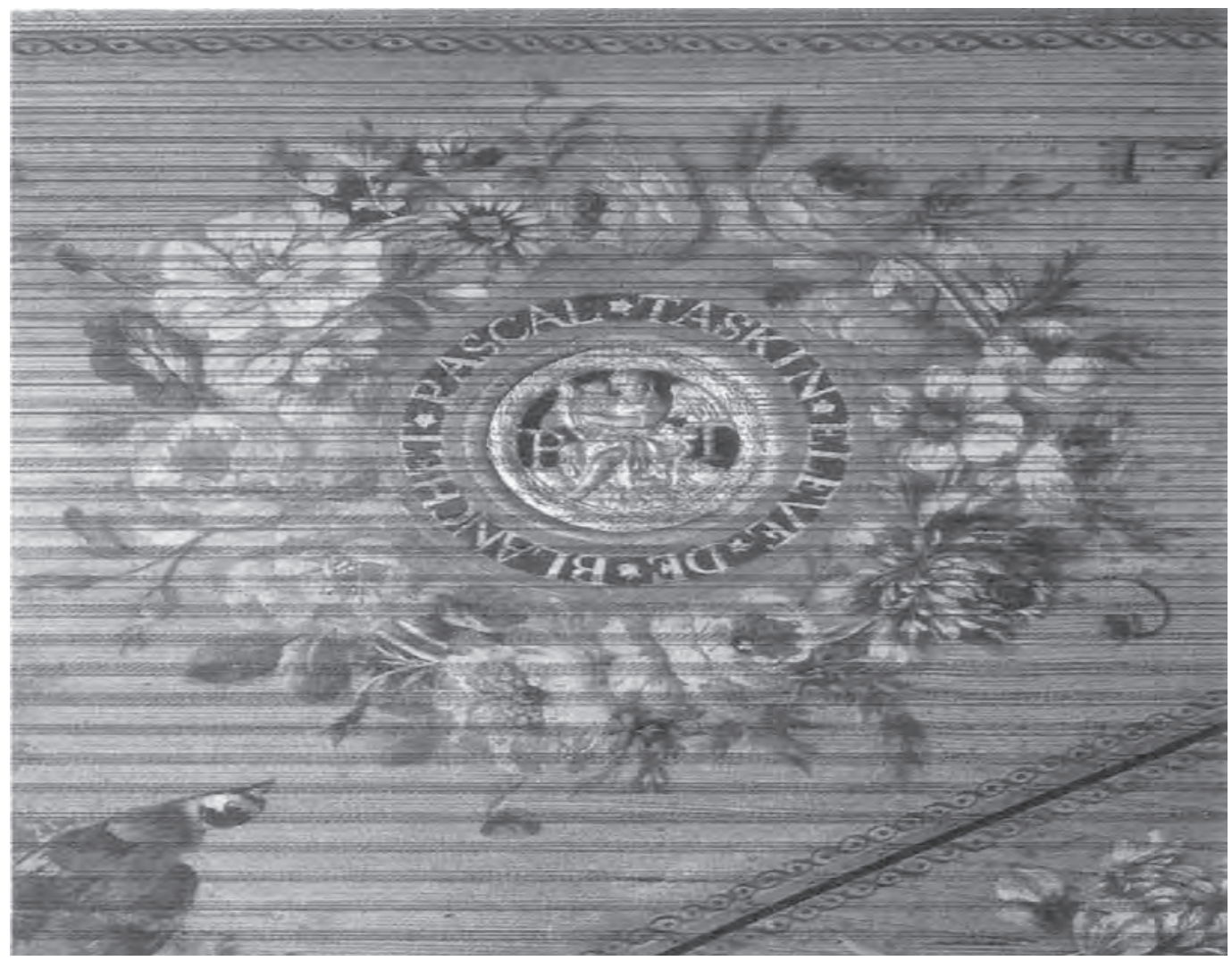

Ex.2 - Rosácea do cravo Taskin, 1769.

(Fonte: Catalog of Russell Collection of Early Keyboard Instruments, 1968. p.35) 
No Ex.3, quatro membros daquela Société aparecem. Laurent Grillet (Vièle a Roue), Louis Diémer (Cravo) Louis van Waefelghem (Viola d'Amore) e Jules Delsart (Viola da Gamba), da esquerda para a direita, compartilham o som do cravo Pleyel, Wolff, Lyon \& Compagnie, construido entre os anos de 1888 e 1891.

Durante a ocupação germânica na França, na Segunda Guerra Mundial, o cravo restaurado por Tomasini foi temporariamente transferido para Viena. Segundo testemunho de RUSSELL, "depois de 1882, ele foi emprestado à firma Erard que desejava copiá-lo com intenções comerciais, e com isto iniciou-se o fazer cravístico moderno". ${ }^{5}$

0 instrumento de Taskin tem cinco oitavas de FF- $f^{\prime \prime}$, com 61 teclas. Três conjuntos de cordas (8', 8' e 4') com dispositivo para efeito sonoro de harpa nos dois 8'. 0 teclado superior, no acoplamento, desliza para dentro. 0 trilho para o registro de 4' fica "entre" os trilhos dos dois 8'. Sua decoração exterior é notável e, de acordo com o estilo Louis XVI, como podemos ver na figura 1, acima. Devido a sua estrutura física - paredes laterais com dimensões arrojadas, ponte de sustentação com menos tensão sobre o tampo harmônico e encordoamento característico (latão e aço) - privilegia os harmônicos superiores, produzindo uma sonoridade muito refinada, delicada e brilhante, ideal para, entre outras, a literatura musical francesa e a do final do século XVIII. Neste sentido, percebemos ainda cuidadosa atenção pelos próprios compositores franceses na utilização de sua região central e grave, propiciando uma pronúncia sonora adequada ao toque legato e cantabile. ${ }^{6}$ Justamente por não evidenciar os primeiros harmônicos, mas sim os harmônicos superiores da série harmônica, estes exemplares propiciaram ainda o uso do modo de tocar conhecido como sur liér (Fr.) ou over legato (Ingl.) que, mais precisamente, utiliza notas sobrepostas umas às outras em acordo com as notas consonantes das harmonias. ${ }^{7}$ Desta forma, o estilo característico de execução da escola francesa do século XVIII, liderados pelos compositores, François Couperin (1668-1733) e JeanPhilippe Rameau (1682-1764), se adéqua perfeitamente ao instrumento, com sua pronúncia vocálica própria e condizente ao padrão das línguas latinas.

\section{2 - A "escola alemã" dos instrumentos conhecidos}

A "escola" de construção dos cravos alemães tem, por outro lado, num primeiro momento, evidente e forte influência da tradição italiana. 0 desenho desenvolvido pelos italianos privilegia - ao contrário dos exemplares franceses - os primeiros harmônicos na produção do som após o pinçamento da corda. Assim, em sua extensão, nota-se claro favorecimento para a execução da polifonia, elemento este, provavelmente, identificado pelos compositores alemães e admitido como característico de sua escola nos séculos XVII e XVIII, para a evidência e entrelaçamento do contraponto composicional. Aliado a isto, percebe-se ainda a presença da escola de construção flamenga e mais precisamente da família Ruckers, que influencia a tradição de construção em todo continente - incluindo-se a já citada tradição francesa - que desenvolveu características próprias, mas, excetuando-se as tradições das penínsulas: itálica e ibérica. Como prova desta troca de influências, mencionamos, entre outros, o exemplar de Johann Christopher Fleischer (Hamburgo, 1710) atualmente no Museu da Filarmonia de Berlim (Ex.4).

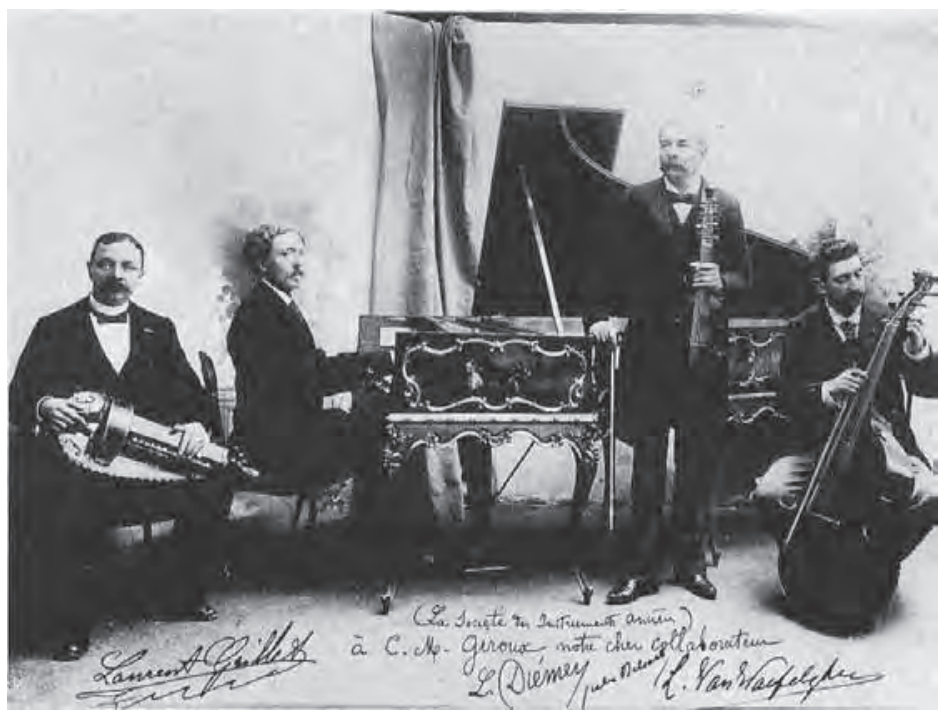

Ex.3 - A Société des Instruments Anciens - Paris, 1895.

(Fonte: Tasteninstrumente. G. Haase und D. Krickeberg. Berlim 1981. p.53) 


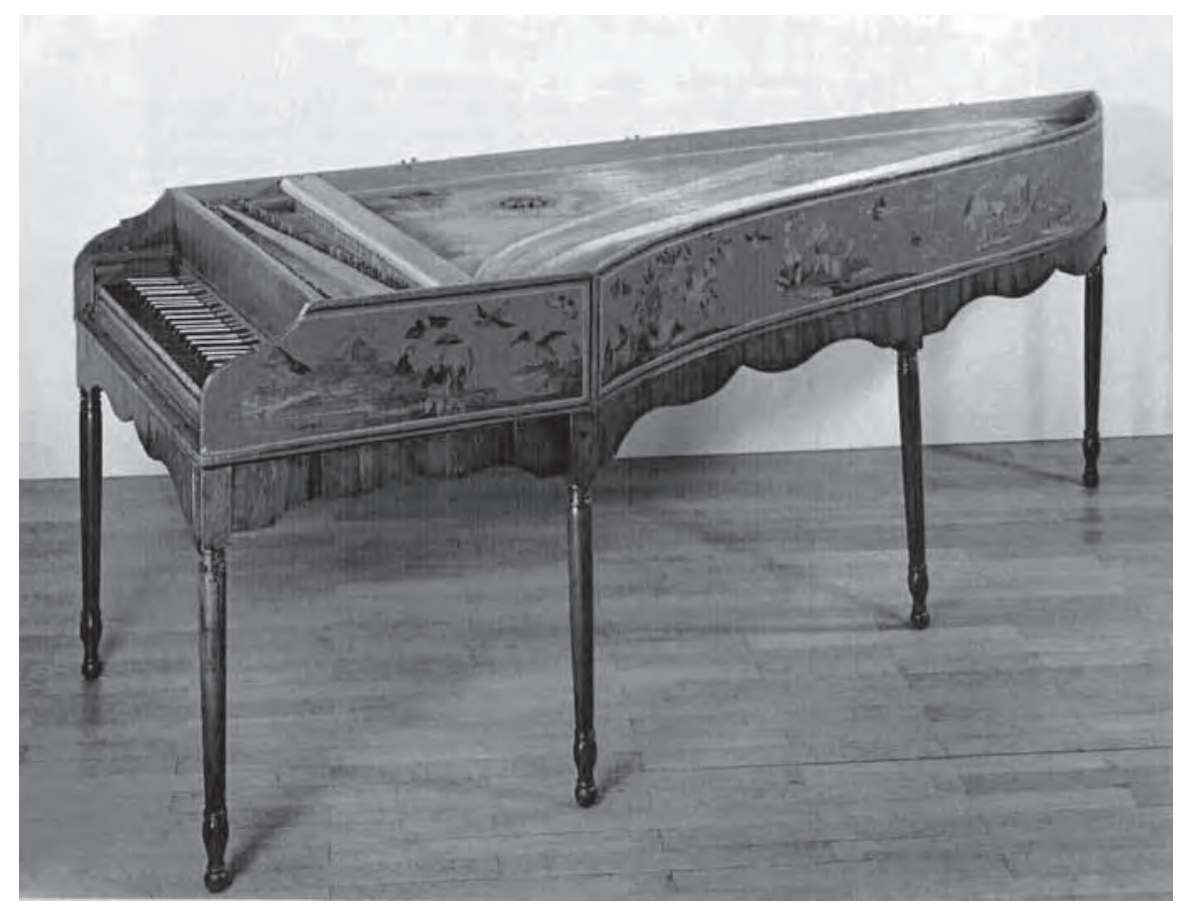

Ex.4 - Cravo Fleischer. Hamburgo, 1710.

(Fonte: Tasteninstrumente. G. Haase und D. Krickeberg. Berlim 1981. p.36)

No ano de 1985, o mundo musical ocidental comemorou os 300 anos de nascimento de Johann Sebastian Bach (1685-1750) trazendo à luz grandes revelações musicológicas. Um dos pontos altos das festividades foi a ênfase dedicada a um exemplar alemão específico. Um instrumento com histórico particular, não assinado e que, de acordo com estudiosos, deve ter sido construído por Michael Mietke (c.1656/1671-1719). Segundo o musicólogo Heinrich Besseler: "Bach em 1718, viajou de Cöthen à Berlim para encomendar este instrumento".8 No entanto, o que se sabe com certeza é que Bach viajou a Berlim em 1719 para avaliar o recém terminado cravo com dois teclados, construído por Mietke e levá-lo para a corte de Cöthen. Atualmente encontra-se um instrumento semeIhante no Schloss Charlottenburg em Berlim (Ex.5), que se acredita ser o referenciado, conforme estudos de Dieter Krickeberg e Sheridan Germann que assim o atestam. ${ }^{9}$

A decoração com fundo negro e em chinoiserie dourada foi realizada por Dagly. ${ }^{10}$ Ele tem dois manuais, extensão de quatro oitavas e meia (Sol a ré'"'), três registros (8', 8' e 4') - estando este último, colocado na terceira posição, como apresentado, proporcionando assim um reforço harmônico aos registros de base. Por se direcionar até o centro do tampo sonoro ou de ressonância, seu volume é mais suave e caloroso. Esta colocação, portanto, difere da construção franco-flamenga que considera sua oitava (o 4') um registro independente e não complementar. Normalmente não existe abafadores em nenhum dos registros de 8 .
A relação a seguir, mostra um considerável número de exemplares significativos para a compreensão de uma provável "escola alemã" de construção. Os dois primeiros são de Michael Mietke. São eles:

01 - Um cravo semelhante ao citado, porém com um manual, cor branca e pertencente à Rainha Sophie Charlotte. Berlim. (Data incerta).

02 - Um cravo com um manual, hoje no Hudiksvall na Suécia, está assinado por Mietke: Berlim 1710.

03 - Um cravo provavelmente pertencente à Wilhelm Friedemann (1710-1784), filho mais velho de J.S.Bach, encontra-se no acervo da coleção de instrumentos do Staatliches Institut für Musikforschung em Berlim, sob o número 316.

04 - Um cravo com manual duplo de Christian Zell (c.1683- 1763) construído em Hamburgo no ano de 1728. ${ }^{11}$

05 - Um cravo Hieronymus Albrecht Hass (1689-1744?) de Hamburgo atualmente no Museu de Instrumentos de Bruxelas na Bélgica. (Dispõe do registro de 16').

06 - Um cravo Johann Heinrich Harrass (1665-1714) da Turíngea e que se encontra no Schlossmuseum em Sondershausen.

07 - Um cravo Gottfried Silbermann (1683-1753).

08 - Um cravo Zacharias Hildebrand (1688-1757). Construtor de Berlim. Bach possuiu dois Lautenwerken seus.

09 - Um cravo Ernst Ludwig Gerber (1746-1819).

10 - Um cravo Johann Christoph Osterlein de 1792. 
Este último exemplar (item 10, mostrado no Ex.6) foi aqui destacado por ter relevância no processo histórico do redescobrimento do cravo no século XX. De fato, este movimento, largamente mencionado, teve seu início já em 1829 liderado por Felix Mendelssohn-Bartholdy (1809-1847), que utilizou o instrumento de Johann Christoph Osterlein (1727-1792) na Sing-Akademie de Berlim, quando da execução da Paixão Segundo São Mateus de Bach.

Independente de sua simples e austera decoração ${ }^{12}$, ele segue o desenho apresentado pelos construtores alemães com dupla curvatura na caixa, dois manuais, três regis- tros (8', 8' e 4') e extensão com cinco oitavas (Fá - f'"). Conveniente ressaltar ainda sua forte semelhança com 0 instrumento de Michael Mietke (figura 5), apesar de sua simplicidade decorativa externa.

A maioria dos instrumentos anteriormente listados possuía a registração padrão com 8' e 4' no primeiro manual, 8' no segundo manual. Em alguns casos, o abafador produzia o "efeito" de alaúde em algum dos manuais e, acoplamento com sistema de gaveta. Poucos exemplares (Harrass e Hass) utilizaram um quarto registro: o 16', muito adequado ao repertório germânico com tradição

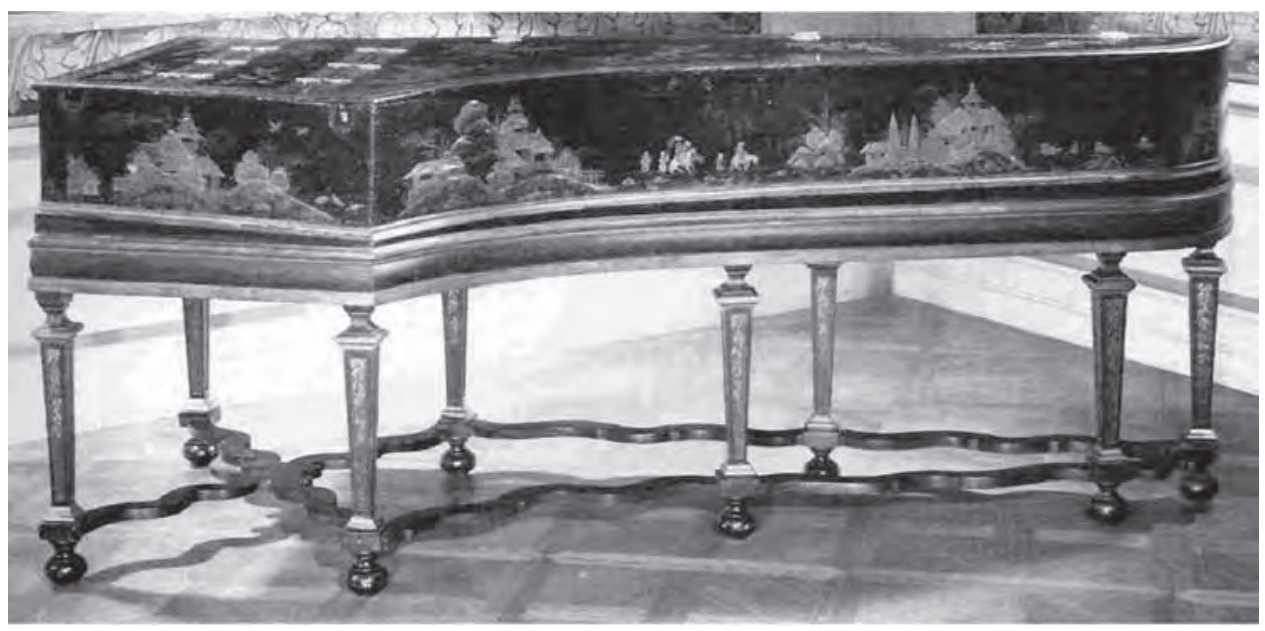

Ex.5 - Cravo com duplo manual atribuído a Mietke. Berlim, 1719.

(Fonte: Chinoiserie. Madeleine Jarry. New York: 1981, p.152)

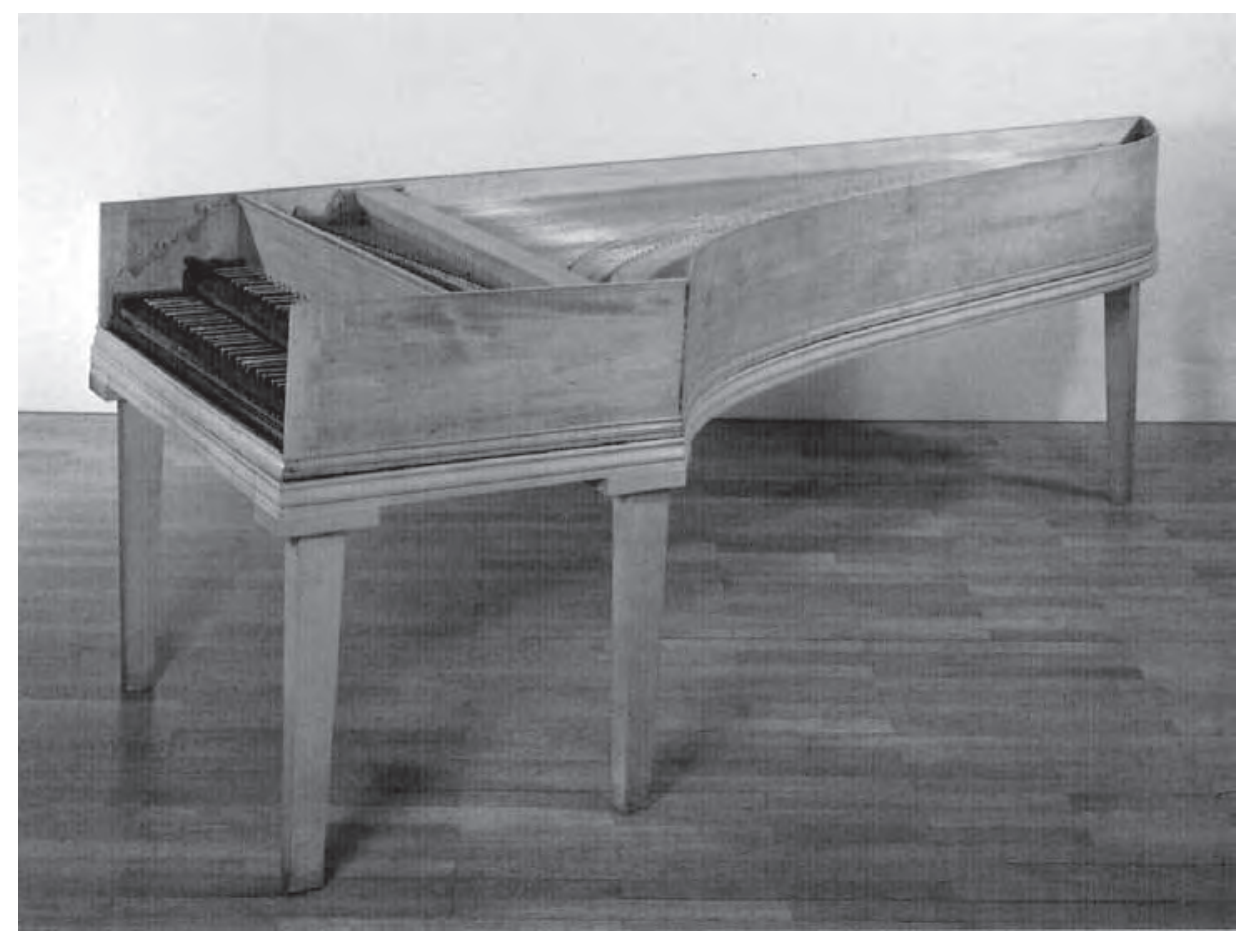

Ex.6 - Cravo Osterlein. Berlim, 1792.

(Fonte: Tasteninstrumente. G. Haase und D. Krickeberg. Berlim, 1981. p.49) 
organística. ${ }^{13}$ Menciona-se ainda a existência de uma pedaleira acoplada, com caixa sonora independente, provavelmente para fins de estudos organísticos, ainda que atualmente não tenha sobrevivido nenhum exemplar contemporâneo.

\section{3 - Sobre a prática musical aplicada}

No que se refere às regras da sintaxe adequadas à prática musical, BADURA-SKODA (2002, p.214) afirmou: "Um conhecimento das regras gramaticais e de vocabulário é um pré-requisito para a comunicação verbal, e mais, nós quase não pensamos em gramática, ao menos, claro, que estejamos falando uma língua estrangeira com a qual não somos familiarizados". Assim, ao identificar a transcrição de uma peça francesa para a linguagem musical alemã, nos perguntamos se: não estaria Bach familiarizando com o estilo estrangeiro francês - ao readequar sua notação ao modo germânico - quando reescreveu o Les Bergeries de François Couperin para o seu Clavierbüchlein ${ }^{14}$ de 1725, livro dedicado à sua segunda mulher Anna Magdalena? Não seria justamente repensar "as regras gramati- cais" o que Bach registra na transcrição do Rondeau Les Bergeries? Inserido na Sixième Ordre para Cravo solo, este Rondeau, na tonalidade de Sib Maior, revela características particulares da "maneira francesa" de composição, com seu caráter Naivement (Ingenuamente) e em acordo ao seu título (Ex.7).

A ornamentação, ligaduras para a articulação dos motivos, entre outros elementos, quando comparados à transcrição bachiana de 1725 (Figura 8), apontam dados relevantes do estilo de execução como, por exemplo, a sugestão para o acompanhamento na mão esquerda nos três primeiros compassos. Também a realização da Tierce coulé (ou o Schleifer alemão) na última colcheia do primeiro compasso na linha melódica, assim o indicam, como podemos visualizar no Ex.8.

De notável interesse ainda é a realização transcrita dos Coulés - ornamentos franceses específicos - na linha melódica do compasso dois, inseridos ao contorno em semicolcheias, revelando uma não sedimentação do Les

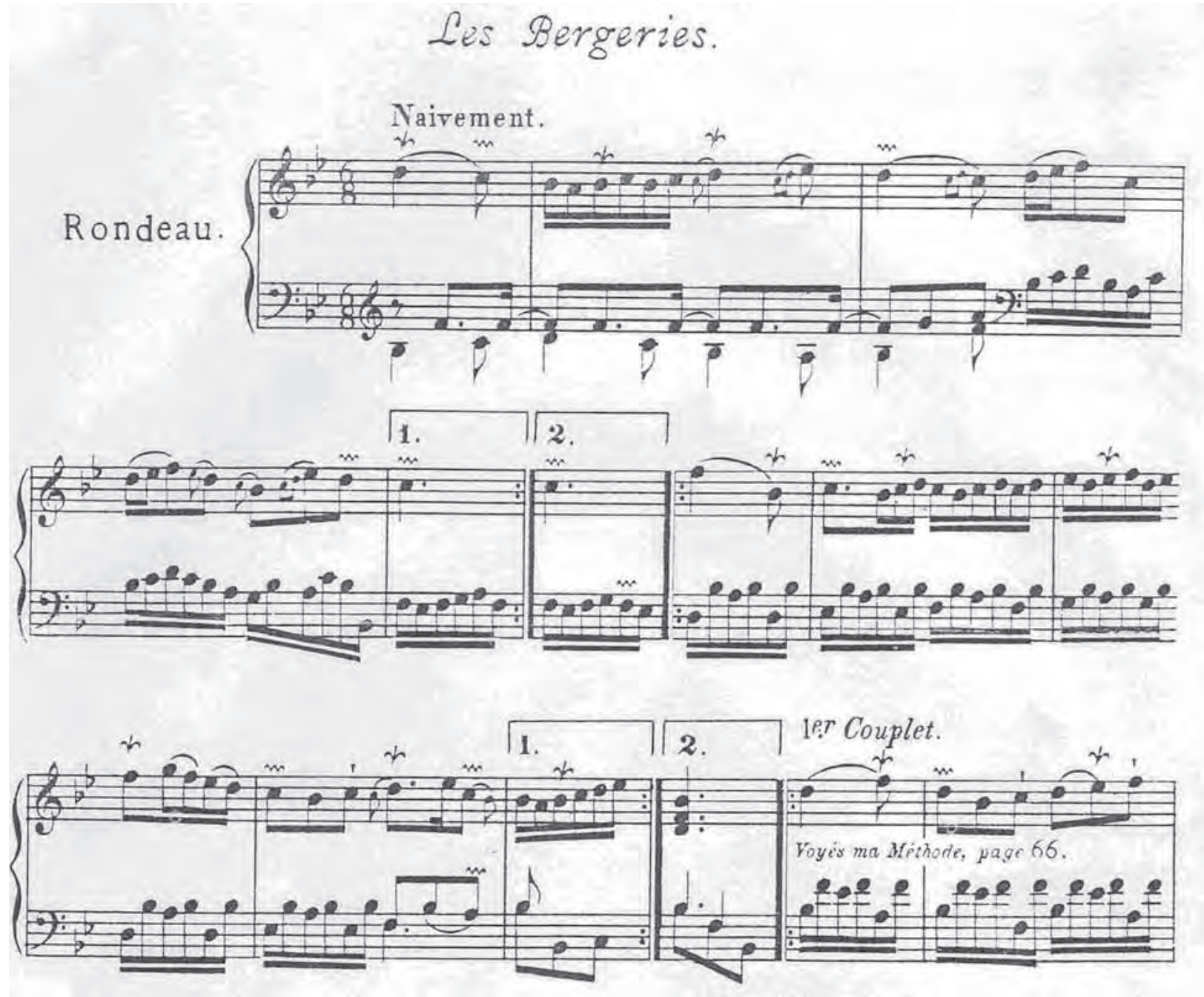

Ex.7 - Rondeau. Les Bergeries. Ordre Sixième de F. Couperin.

(Fonte: Edição Dover, New York) 


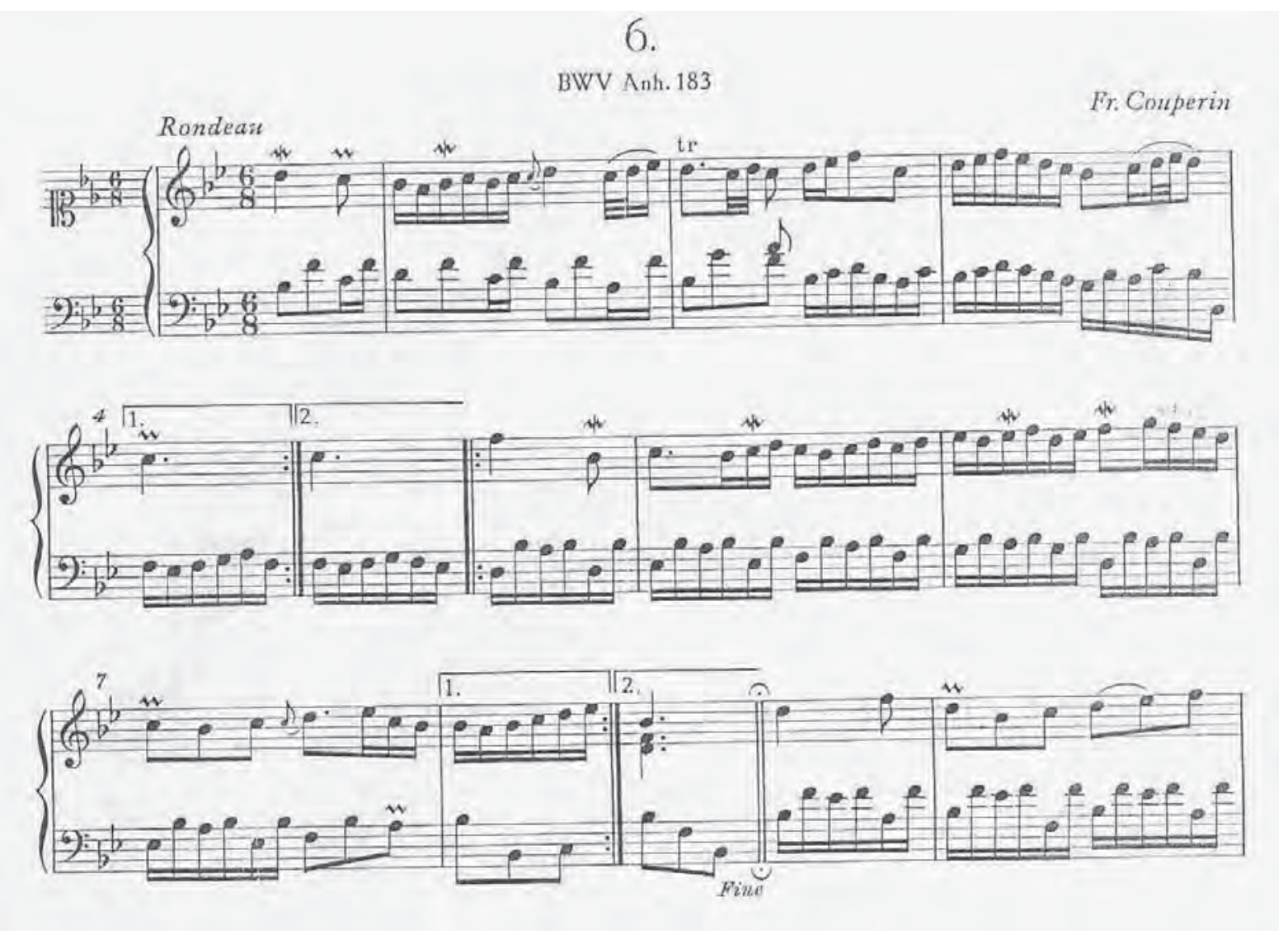

Ex.8 - 0 Rondeau de F. Couperin transcrito por J. S. Bach.

(Fonte: 0 Clavierbüchlein para Anna Magdalena Bach. Ed. Bärenreiter)

Goûts-Reunis, ${ }_{1}^{15}$ proposto musicalmente em 1724 por F. Couperin, em 1728 por J.D. Heinichen (1683-1729) e em 1752 por J.J.Quantz (1697-1773). Muito particular também é a identificação das notas finais da tônica na linha do baixo, no compasso oito (casas 1 e 2), próprias da pontuação cadencial que preparam a reprise. Notese que Bach modificou a figuração rítmica francesa de ressonância, indicando assim, o hábito germânico para o tratamento da linguagem e articulação dos motivos rítmicos e melódicos.

Sabe-se que Bach nunca viajou a França e que muito aprendeu sobre estilos nacionais ${ }^{16}$ por meio das partituras disponíveis e das esparsas eventuais audições de músicos franceses. A mais notável foi a célebre competição que travaria com Louis Marchand (1669-1732) ${ }^{17}$. Notável também identificar a presença de um exemplar do Second Livre de pieces de clavecin de F. Couperin (Paris, 1716 e 1717), em sua Biblioteca particular. Assim, ao perceber as modificações por ele realizadas, notamos uma sedimentação do "estilo germânico" de execução e mais precisamente, do estilo non legato, propagado por Friedrich Wilhelm Marpurg (1718-1795) ${ }^{18}, \mathrm{C}$. Ph. E. Bach ${ }^{19}$ e D.G.Türk (1750-1813) ${ }^{20}$.

\section{4 - Sobre a pronúncia atribuída ao toque germânico}

No que se refere à Marpurg, é curioso perceber que o título do seu tratado Die Kunst das Clavier zu spielen, publicado em Berlim no ano de 1750, é uma tradução literal daquele de Couperin L'Art de toucher le Clavecin (Paris 1716/17), embora Clavier, na Alemanha do século XVIII, se referisse aos teclados em geral, incluindo-se, obviamente o Clavicórdio, pouquíssimo mencionado na França da época. Ainda sobre este aspecto, deve-se dizer que Couperin não considerou a possibilidade generalizada como o fez Marpurg - da passagem ascendente (na mão direita) do dedo médio por cima do anular $(3,4,3,4)$ e a passagem descendente do dedo médio sobre 0 indicador $(3,2,3,2)$, uma divergência estilística significativa para a pronúncia dos motivos melódicos e um resquício dos dedilhados antigos. ${ }^{21}$ Couperin assume outros padrões digitais que irão proporcionar uma adequação ao seu próprio estilo, determinando uma projeção silábica e motivos melódicos, coerentes com sua língua materna, portanto, um toque direcionado ao cantabile. ${ }^{22}$ Mais tarde, em 1802, J.N.Forkel disse: "0 impulso ou a quantidade de pressão comunicada à tecla deve manter-se com igualdade. Para isto, o dedo não deve levantar-se perpendi- 
cularmente das teclas, porém, deslizar-se suavemente ao longo da mesma, gradualmente, em direção à palma da mão".23 Com isto, observando-se o movimento indicado, adquire-se a técnica pertinente à estética alemã. Ainda mais, esta prática "ideal" adéqua-se ao tipo de formato dos teclados germânicos - que, para as notas diatônicas, assim se apresentam: encurtados em seu comprimento e alargados no sentido lateral, e para as teclas acidentadas outro desenho, diferente dos padrões em pirâmide, conhecidos atualmente. Dessa forma, torna-se difícil a inserção dos dedos por entre estas mesmas teclas alteradas, e faz-se com que os padrões de dedilhados atuais para as escalas, como: 1, 2, 3, 1, 2, 3, 4, em tonalidades com mais de 3 acidentes, por exemplo, devam ser repensados quanto ao modelo antigo $(1,2,3,4,3,4,3,4) \mathrm{em}$ tonalidades naturais. Assim, compreendem-se de maneira mais sedimentada as práticas descritas textualmente por QUANTZ (1752) e mais tarde por FORKEL (1802), ao enfatizar unanimemente o "puxar os dedos para fora das teclas em direção à palma da mão". ${ }^{24}$

Para a escola francesa, a particularidade no tipo de toque e sua utilização, tornam clara a diferença que é dada a uma liaison (ligação), justificando o dedilhado com a exigência de uma execução em legato com a troca "muda" dos dedos. Já para os alemães, conforme MARPURG (1762, p.28), o Schleiffen (deslizar) e o Abstossen (afastar, desligar) vêm assinalados no texto musical como exceções, sendo, portanto, requeridos pelos autores em efeitos especiais. São suas variações: Schleiffen com o meio-arco (halben bogen) e Abstossen com o ponto (punkt) ou com um pequeno traço (Strich). 0 Schleiffen significa não erguer o dedo da nota anterior até que a próxima seja tocada. Já o Abstossen consiste em segurar uma nota não segundo seu valor real, mas somente "pela metade dele". ${ }^{25}$ Assim, entre as duas formas excepcionais de toque, pode-se imaginar a execução regular e comum, o correspondente ao conhecido non-legato, que Marpurg chamou de "fluindo regularmente", e que é a forma de toque "sempre presumida" (MARPURG, p.29). Ele assim a descreve: "devese erguer o dedo da tecla anterior com agilidade pouco antes que a nota seguinte seja tocada" (p.29). ${ }^{26} \mathrm{Em}$ seu Anleitung zum Claviersplielen de 1755, ele disse: "oposto ao legato como também ao staccato é o movimento ordinário [o qual, na ausência de indicações mencionadas ao contrário] está sempre compreendido" (p.30). Também TÜRK (1798, p.356) afirmou: "Se as notas tiverem que ser tocadas no modo comum, isto quer dizer, nem staccato nem "legato", os dedos devem levantar um pouco antes que seus comprimentos [reais] sejam terminados. FORKEL (1802, p.140) também apresenta o mesmo sentido quando disse: "...de tal maneira que os dois sons não estarão destacados, nem ligados um ao outro. A pulsação não será então, nem empastada nem por demais breve". Portanto, podemos concluir que a execução em non-legato era, ao contrário da França, o tipo de toque comum e mais utilizado no norte da Alemanha. Digno de nota é a advertência que Marpurg fez, ao já antes mencionado por C.Ph.E. Bach (1753) ${ }^{27}$, um tipo de "execução pegajosa" (klebrichte Spiel-Art), um mau costume de alguns em manter uma tecla presa por tempo maior do seu valor.

\section{5 - Conclusão}

Obedecendo a um determinado preceito estético, percebemos que, por meio da identificação dos valores musicais específicos de cada cultura, os compositores buscavam uma coerência com sua própria língua falada, transportando para as suas obras musicais os preceitos da "sintaxe" na formação do discurso eloquente. Dessa maneira, utilizarem-se dos recursos técnicos particulares - ligaduras de "duas a duas notas sur lier", para o caso francês e notas em "toque destacado" advindas do Abstossen para o caso alemão - revelam uma coerência estilística corroborada ainda pela produção e natureza sonora de seus próprios instrumentos, especialmente no período que denominamos de "alto barroco" ou barroco tardio. Tanto a produção cravística de Johann Sebastian Bach quanto a de François Couperin devem ser consideradas como os "principais pilares" nas quais se sustentam a compreensão da linguagem do barroco e suas particularidades estilisticas. Assim, torna-se impossivel ignorar a sonoridade brilhante e "calorosa" do cravo francês do século XVIII (Blanchet, Taskin, entre outros) e, da mesma forma, a vertente alemã (Vater, Mietke, entre outros), com sua sonoridade pulsante e marcada, ideal para a polifonia germânica. Certamente não foi por casualidade que o próprio Bach registrou em seu Concerto nach Italienischen Gusto und einer Overture nach Französicher Art Zweyter Theil der Clavier Ubung (1735) BWV 971 e 831, os estilos: italiano e francês, preconizando a futura estética do Les Goûts Reunis, codificada por Quantz. Que Bach conheceu diferentes e diversos tipos de instrumentos com as mais relevantes variedades, isso se pode afirmar, ainda que ele próprio não tenha tido a fortuna de possuí-los. Sua visita a Potsdam em 1747 certamente confirmou sua atitude "visionária" (Musikalische Opfer - BWV 1079) e nos deixou um legado musical dos mais variados em estilo e amalgamação estética. 


\section{Referências}

BACH, Carl Philipp Emanuel. Versuch über die wahre Art das Clavier zu spielen. Berlim 1753. Leipzig: Breitkopf \&t Härtel, 1969.

BADURA-SKODA, Paul. Interpreting Bach at the Keyboard. Oxford: Clarendon Press., 2002.

COUPERIN, François. L'Art de toucher le Clavecin Paris, 1716 e 17. Ed. Fac-similar.

FORKEL, Johann Nikolaus. Über Johann Sebastian Bachs Leben, Kunst, und Kunstwerke. Leipzig: 1802. Reimpressão: Kassel: Bärenreiter-Verlag, 1968. Tradução inglesa por David and Mendel.

HAASE, Gesine und Dieter Krickeberg. Tasteninstrumenten. Berlim: Staatliches Institut für Musikforschung, 1981.

JARRY, Madeleine. Chinoiserie. Chinese Influence on European Decorative Art, $17^{\text {th }}$ and $18^{\text {th }}$ Centuries. Translated by Gail Mangold-Vine. New York: The Vendome Press, 1981.

MARPURG, Friedrich Wilhelm. Die Kunst das Clavier zu spielen. Berlim: Houde und Spener. 1755 e 1762. Cópia fac-similar.

NEWMANN, Sidney and Peter WILLIAMS. The Russell Collection of Early Keyboard Instruments. Edinburgh: Edinburgh University Press, 1968.

QUANTZ, Johann Joachim. On Playing the Flute. Translated by Edward R. Reilly. London: Faber and Faber, 1976.

RAMEAU, Jean-Philippe. De la Méchanique des doigts sur le clavecin. Paris, 1724. Ed. Facsimilar.

RASE, Horst \& DROYSEN-REBER, Dagmar. Kielklaviere. Berlim: Staatliches Institut für Musikforschung, 1991. RUSSELL, Raymond. The harpsichord since 1800. In Proceedings of the Royal Musical Association. 1955-6. p.61.

TÜRK, Daniel Gottlob. Klavierschule oder Anweisung zum Klavierspielen für Lehrer und Lehrnende. Leipzig: 1798. R. H. Haggh: School of Clavier Playing, University of Nebraska, 1982.

\section{Notas}

1 Taskin nasceu em Theux perto de Liège na Bélgica. Quando jovem ele mudou-se para Paris e trabalhou no Atelier de François-Etienne Blanchet (1761) e do filho dele François-Etienne filho (1730-1766). Quando este morreu Taskin casou-se com sua viúva e o sucedeu nos negócios. 0 sobrinho de Taskin, também chamado Paschal-Joseph, também se casou com a enteada do seu tio mantendo assim o nome da família. Seus instrumentos podem ser atualmente encontrados na coleção do Conservatoire de Paris.

2 Maiores detalhes sobre a formação desta coleção pode-se encontrar em: The Russell Collection of Early Keyboard Instruments. Edinburgh University Press, Edinburgh, 1968.

3 Os membros da família Blanchet foram construtores de cravos desde o século XVII até metade do século XIX, quando se tornaram construtores de piano. François-Étienne (c.1700-1761), o mais relevante para o nosso estudo, foi responsável por muitos ravalements (modificações técnicas), principalmente em instrumentos flamengos e mais especificamente os de Ruckers.

4 Provavelmente o primeiro músico profissional a se apresentar ao Cravo antes de Wanda Landowsa (1879-1959), que nesta época tinha apenas 10 anos de idade.

5 Digno de nota é o artigo de R. Russell The harpsichord since 1800. In: Proceedings of the Royal Musical Association. 1955-6. P.61.

6 Note-se já aqui a nova preocupação e coerência estética com este tipo de toque, que será enfatizado pelos teóricos franceses do período, iniciado por F. Couperin em seu L'Art de toucher le Clavecin. Paris, 1716 e 17.

7 Algumas tabelas de ornamentação tais como a de J. Ph. Rameau apresenta este tipo de execução ilustrado pela grafia musical. De la Méchanique... Paris, 1724.

8 Margraf Christian Ludwig von Brandenburg. BJb, 43 (1956). P.18-35.

9 Maiores informações podem ser adquiridas na nota 19 à página 152 do estudo Interpreting Bach at the Keyboard realizado por Badura Skoda que esclarece preciosas informações.

10 Gerhard Dagly (1650-1728). Mestre importante em trabalhos laqueados com Chinoiserie no Shloss Charlontenburg de Berlim.

11 Apresentado na Exposition Universele de Paris em 1900, como parte da coleção de A. Thibout, fazendo "falsa" alusão a um instrumento francês do século XVII, provavelmente por sua decoração rebuscada. Hoje pertence à coleção de instrumentos do Museum für Kunst und Gewerbe (Artes e Ofícios).

12 Note-se que, apenas alguns detalhes em recortes artísticos foram inseridos na sua parte interna.

13 Ainda que raro, o registro de 2 ' esteve presente em poucos exemplares.

14 Refere-se aos dois cadernos manuscritos que o autor presenteou sua mulher. Eles são conhecidos pelas datas de suas páginas de título, 1722 e 1725. 0 Pequeno livro é usado para se referir ao último deles.

15 Esta se tornará uma característica do estilo posterior pela reunião de estilos: o italiano e o francês. Com este título e estas obras Couperin empenha-se em sua intensificação. Mais tarde Quantz registra sua importância em seu tratado Versuch einer Anweisung.... Berlim,1752.

160 Concerto nach Italienischen Gusto (BWV 971) e a Ouverture nach Französischer Art (BWV 831) foram publicados como Clavierübungen II (1735) e assim o demonstram.

17 De acordo com o "Obituário" de 1754: Quando em visita a Dresden na corte do Eleitor da Saxônia, no outono de 1717, Marchand abandonou o local da competição após ter ouvido Bach em seu estudo prático preparatório, retornando à Paris sem comparecer ao encontro.

18 P.29. 
19 Versuch... (Mitchel), p.42-43.

20 Para Türk, no entanto, as pausas entre as notas, se comparadas aos ensinamentos de C.P.E. Bach, são mais curtas.

21 Note-se que, J. S. Bach ilustra esta problemática em seu Aplicatio (1720) no caderno de W. Friedemann e seu filho C.P.E. Bach o menciona como alternativa no Capítulo sobre Dedilhados do seu tratado de 1753.

22 Convém ressaltar aqui que este tipo de toque não se restringe apenas à música francesa, contudo, caracteriza a sonoridade para os repertórios com influência latina, preconizada pela Itália.

23 Orientação de número dois indicada por Forkell e segundo instruções de C. P. E. Bach, para a maneira pela qual, seu pai, J.S. Bach tocava os instrumentos de teclado.

24 Quantz, Versuch, 1752, apud The Bach Reader. Hans T. David and Arthur Mendel, 1966. p.444.

25 Marpurg, 1762 p.28.

26 Man muss ganz hurtig kurz vorher, ehe man die folgende Note berühret, den Finger von der vorgehenden Taste aufheden.

27 "muitas pessoas tocam como se tivessem cola nos dedos, e muitas vezes, seguram as teclas mais tempo do que o necessário". Apud J.N.Forkel: Sobre a Vida a Arte e as Obras de J. S. Bach. Capítulo III - Bach nos instrumentos de Teclado. Leipzig, 1802. (Tradução Livre do autor).

Edmundo Hora, Doutor em Cravo pela Unicamp, graduou-se como "Solista ao Cravo" pela Escola Superior de Artes de Amsterdã e pós graduou-se na Hogeschool Stichting Amsterdam - Sweelinck Conservatorium (1984 a 1993), orientado por J. Ogg e A. Uittenbosch, tendo em seu exame final, presidente do júri, Gustav Leonhardt. Professor e palestrante: Festivais de Londrina PR (1984 a 1991); Encontros de Música Antiga e Oficinas de Música de Curitiba-PR (1994 a 2002); Música Colonial Brasileira e Música Antiga de Juiz de Fora-MG (1990 a 2002); Simpósio de Musicologia da UNIRIO-RJ; I, II, III e IV Simpósio Latino Americano de Musicologia da Fundação Cultural de Curitiba-PR; VI Festival Internacional de Música Sacra de Quito - Equador 2007; Simpósio Internacional de Cognição e Artes Musicais SINCAM - UFBA 2007, USP 2008, UFG 2009 e UFRJ 2010; Encontros de Música Antiga de Recife/Olinda 2007, 2008, 2009 e 2010. Professor de Cravo no Departamento de Música do Instituto de Artes da Unicamp desde 1993 atua ainda no Programa de Pós-Graduação em Música na mesma Universidade. 